Proceedings

\title{
Quantitative Crystal Structure Analysis of Complex: tris((1-((E)-o-tolyldiazenyl)naphthalen-2-yl)oxy)cobalt
}

$\dagger$

\section{A. Benosmane ${ }^{1,2, *}$, C. Boukentoucha ${ }^{2}$ and M. A. Benaouida ${ }^{2}$}

1 Larbi Ben M'hidi University, Oum El-Bouaghi 04000, Algeria

2 Unit of Environmental Chemistry and Structural Molecular, Constantine1 University, Constantine 25000, Algeria

* Correspondence: benosmanekhaled@gmail.com

+ Presented at the 24th International Electronic Conference on Synthetic Organic Chemistry, 15 November-15 December 2020; Available online: https://ecsoc-24.sciforum.net/.

Received: date; Accepted: date; Published: date

\begin{abstract}
Recently, azo derivatives have attracted attention because the phenylazo-naphtholate group can provide N,O-bidentate chelation to stabilize transition or main group metal complexes. azo derivatives and their metal complexes are very important pigments for synthetic leather and vinyl polymers. On the other hand, Azo-metal chelates are known to be involved in a number of biological reactions, such as inhibi- tion of DNA, RNA, and protein synthesis, nitrogen fixation, and carcinogenesis. Furthermore, high-density optical data storage has been a subject of extensive research in the past decade.The present work aimed chiefly to throw more light on the Structural characterization of the title mononuclear $\mathrm{Co}(\mathrm{II})$. The coordination behaviour of this azo compound towards $\mathrm{Co}(\mathrm{II})$ ion is reported using different analytical tools of single crystal X-ray diffraction analysis. Furthermore, the role of weak intermolecular interactions in the crystal packing has been analysed.
\end{abstract}

Keywords: Azo compounds; Metal complexes; crystal structures

\section{Introduction}

The development of metal complexes based on azo compounds has grown considerably in recent years. This is due to the diversity of the fields of application offered by these compounds. One of the most important areas where coordination compounds contain azo compounds is used in textile chemistry.

They are mainly based on chromium, copper, cobalt, nickel....etc. They are used for coloring cotton, wool, polyamide, leather. Indeed, these materials have the advantage of being able to combine the properties from the organic compound and the inorganic compound, while giving hope for a synergy between these two properties.

Metal complex dyes exhibit excellent unison dyeing and penetration characteristics and utilize the ability to cover surface irregularities. They have good light fastness and wash fastness properties even for dark shades.

We develop in the following the synthesis of an organic-inorganic hybrid material based on an azo compound using cobalt acetate. In which it will be treated by a detailed study of the crystal structure by X-ray diffraction, the spectroscopic methods; infrared and proton nuclear magnetic resonance. 


\section{Experimental}

Our monoatomic Cobalt (II) complex was prepared by adding $0.003 \mathrm{~mol}$ of the ligand 1(o-tolyldiazenyl) naphthalen-2-ol to $0.001 \mathrm{~mol}$ of $\mathrm{Co}(\mathrm{OAc}) 2.4 \mathrm{H}_{2} \mathrm{O}$ in a mixture of THF/MeOH (10/10 $\mathrm{mL}$ ). The reaction mixture remained under stirring for $12 \mathrm{~h}$ at room temperature. Volatiles were removed in vacuo.

Brown crystals were obtained after a period of a few days by slow evaporation of the solution at room temperature. These could be isolated under an optical microscope for further X-ray analysis. The reaction scheme for the different stages of the synthesis of our complex is shown Scheme 1 below:
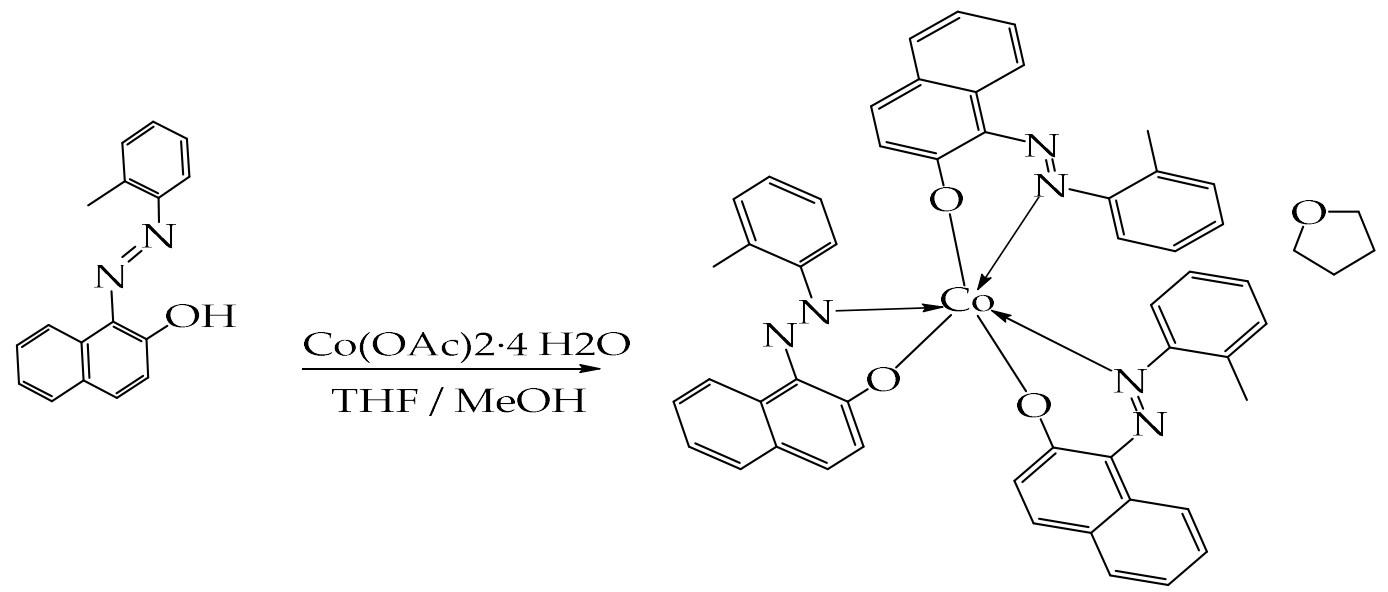

Scheme 1. Synthesis of complex.

\section{Results and Discussion}

The functional groups have been identified using infrared spectroscopy and proton nuclear magnetic resonance.

\subsection{Infrared Spectra}

The infrared spectrum of this compound show a band located at $1360 \mathrm{~cm}^{-1}$ which is attributed to the $\mathrm{N}=\mathrm{N}$ function, an absorption around $1144 \mathrm{~cm}^{-1}$ is due to the band of the $\mathrm{CN}$ bond, a band appearing at $1211 \mathrm{~cm}^{-1}$ is attributed to the mode of vibration of the $\mathrm{CO}$ bond (aromatic). In the spectra is the usual modes of aromatic ring vibrations and these reveal small shifts in the complex than in the free ligand, which is due to the expected electronic structure changes upon coordination. The proposed assignments are based on previous results and pertinent bibliography. While bands have a frequencies $630 \mathrm{~cm}^{-1}$ and $563 \mathrm{~cm}^{-1}$ indicating coordination through the oxygen atom and the nitrogen atom.

\subsection{NMR spectra}

In the $1 \mathrm{H}$ NMR spectrum the multiplets at 6 - 8 ppm corresponds to the aromatic protons. The disappearance of the signal at around $16 \mathrm{ppm}$ belongs to the labile $\mathrm{H}$ of the hydroxyl $(\mathrm{O}-\mathrm{H} \cdots \cdots \mathrm{N})$ ligand, thus confirming the formation of the Co-O coordination, in place of $\mathrm{H}-\mathrm{O}$.

\subsection{X-ray Diffraction}

The crystal of the compound tris((1-((E)-o-tolyldiazenyl)naphthalen-2-yl)oxy)cobalt, was obtained in a test tube from a ethanol saturated solution through the slow evaporation of the solvent; the crystals were dried and separated for analysis of X-ray diffraction.

The crystalline data for this compound can be seen in Table 1 The complex crystallizes in a monoclinic system $\mathrm{a}=11.114$ (3) $\AA \mathrm{b}=180.690$ (5) $\AA \mathrm{c}=22.229$ (6) $\AA$, $\beta=110.015^{\circ}$, presenting space 
group P21/c with Z equal to 4 repeat units per unit cell, which comprises a volume of $4338.8 \AA^{3}$. Figure 1 represents the repeat unit of the complex formed.

Table 1. Crystal data of Cobalt complex.

\begin{tabular}{|c|c|}
\hline Chemical formula & $\mathrm{C}_{55} \mathrm{H}_{47} \mathrm{CoN}_{6} \mathrm{O}_{4}$ \\
\hline weight $(\mathrm{g} / \mathrm{mol})$ & 914.54 \\
\hline \multirow{3}{*}{ Unit cell dimensions } & $\mathrm{a}=11.1142(3) \AA$ \\
\hline & $\mathrm{b}=18.6906(5) \AA \quad \beta=110.015(2)^{\circ}$ \\
\hline & $c=22.2292(6) \AA$ \\
\hline Crystal system & Monoclinique \\
\hline Space group & $\mathrm{P} 21 / \mathrm{c}$ \\
\hline $\mathrm{V}\left(\AA^{3}\right)$ & $4338.8(2)$ \\
\hline Z & 4 \\
\hline $\mathrm{D}_{\text {cal }}\left(\mathrm{g} / \mathrm{cm}^{3}\right)$ & 1.4 \\
\hline Absorption coefficient $(\mathrm{mm}-1)$ & 0.45 \\
\hline $\mathrm{F}(000)$ & 1912 \\
\hline$R\left[F^{2}>2 \sigma\left(F^{2}\right)\right]=0.046$ & $\begin{array}{c}\mathrm{w}=1 /\left[\sigma^{2}\left(\mathrm{Fo}_{\mathrm{o}}^{2}\right)+(0.0608 \mathrm{P})^{2}+4.0091 \mathrm{P}\right] \\
\text { avec } \mathrm{P}=\left(\mathrm{Fo}^{2}+2 \mathrm{~F}^{2}\right) / 3\end{array}$ \\
\hline$w \mathrm{R}\left(\mathrm{F}^{2}\right)=0.126$ & $(\Delta / \sigma)_{\max }=0.008$ \\
\hline$S=1.04$ & $\Delta Q_{\max }=0.67{\mathrm{e} \AA^{-3}}^{\circ}$ \\
\hline $\begin{array}{l}7669 \text { No. of measured, independent } \\
\text { and } \\
5980 \text { observed reflections }[\mathrm{I}>2 \sigma(\mathrm{I})]\end{array}$ & $\Delta Q_{\min }=-0.52 \mathrm{e} \AA^{-3}$ \\
\hline
\end{tabular}

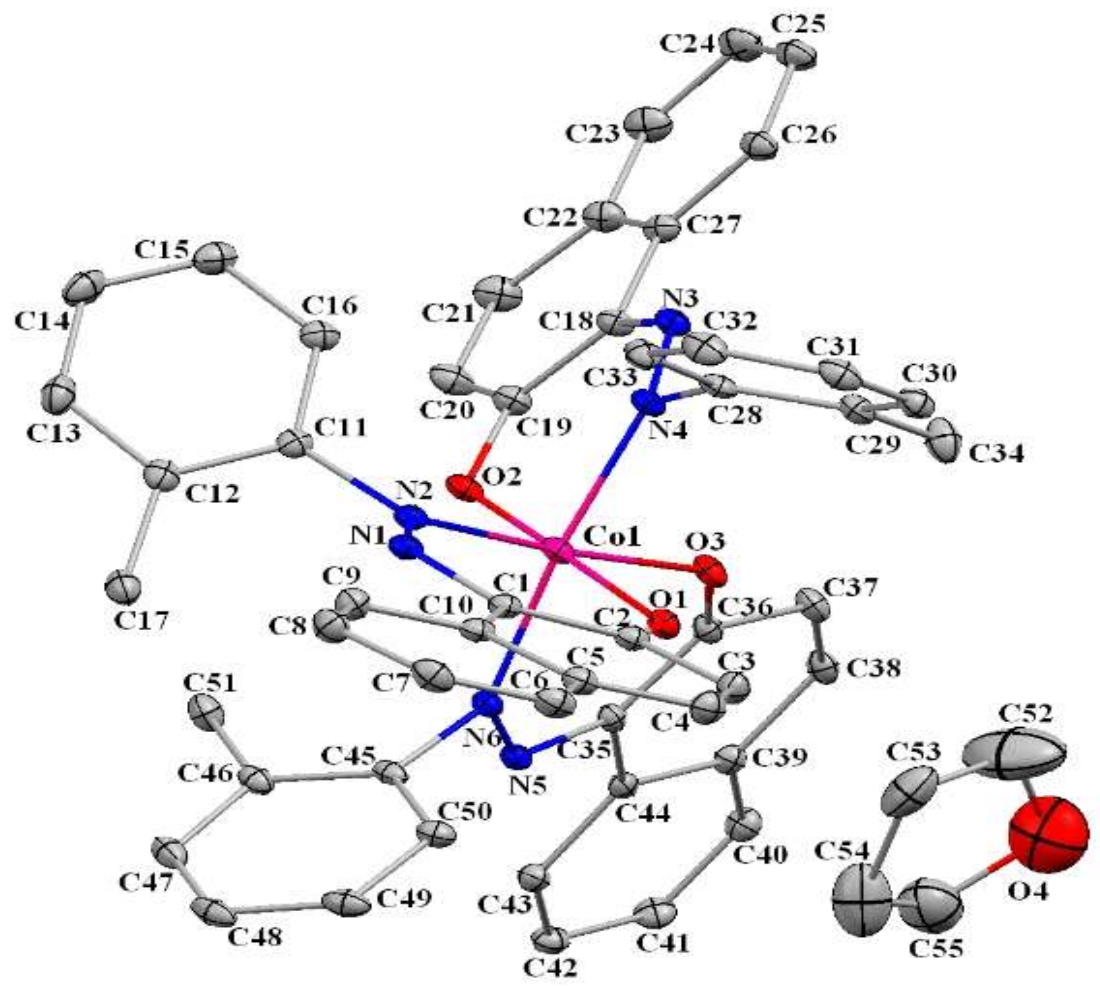

Figure 1. The asymmetric unit of Cobalt (II) complex (H atoms have been omitted for clarity).

For this compound the building block was formed through the coordination between three azo dyes and the cobalt ion; the metallic site appears coordinated in an octahedral geometry slightly 
distorted, with the bond angles between the O1-Co-O3, O2-Co-O3, N2-Co-N4 and N2-Co-N6 atoms presenting values of $86.39^{\circ}, 87.38^{\circ}, 92.71^{\circ}$ and $95.75^{\circ}$ respectively. However, we notice that the angles (O-Co-N) have values varying between $82.32^{\circ}-93.77^{\circ}$.

The structure described here of the ML $3 \times 3$ type presents three bidentate ligands and it exists in the form isomer (mer) in which the two of the three identical atoms (O1; O2; O3 or N2; N4; N6) are Trans and therefore these three Identical atoms are on the same plane passing through the metallic center.
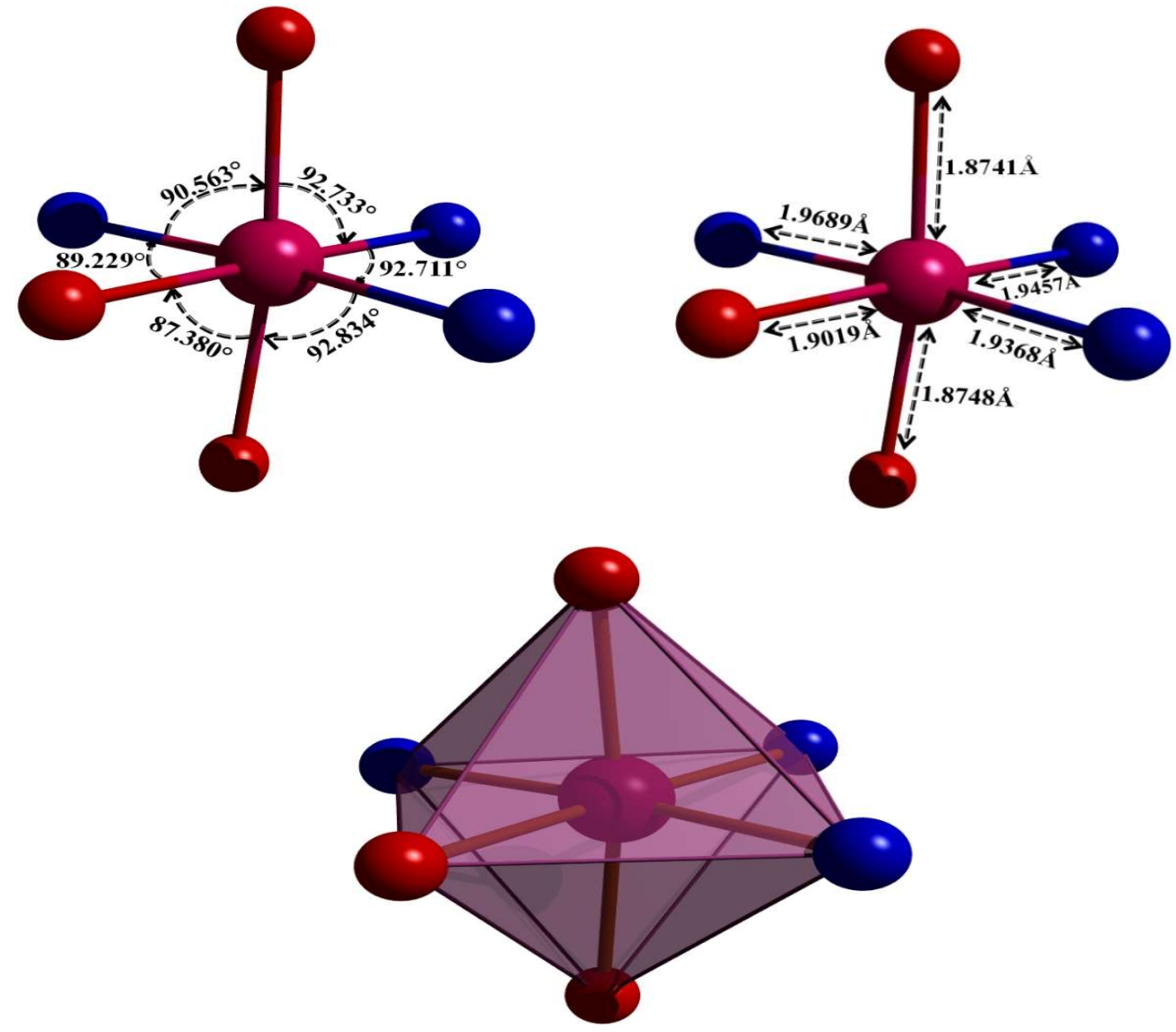

Figure 2. Environment of the cobalt atom.

The solid state arrangement displays supramolecular interactions of the p- stacking type between the rings of the benzene group $(\mathrm{Cg} 9, \mathrm{Cg} 12)$ and the center of gravity $\mathrm{Cg} 1$ which represents the center of the ring (Co O1 C2 C1 N1 N2). The distance between the two centroids from the naphthol groups (opposite rings) is $3.534 \AA$ and $3.834 \AA$. Further interaction is observed between the $\mathrm{Cg} 9$ center of gravity of the benzene ring, with the $\mathrm{Cg} 4$ center of gravity of the naphthalene ring with a distance of $3.759 \AA$, these interactions play an important role in the structural stability of the complex (Figure 3). 

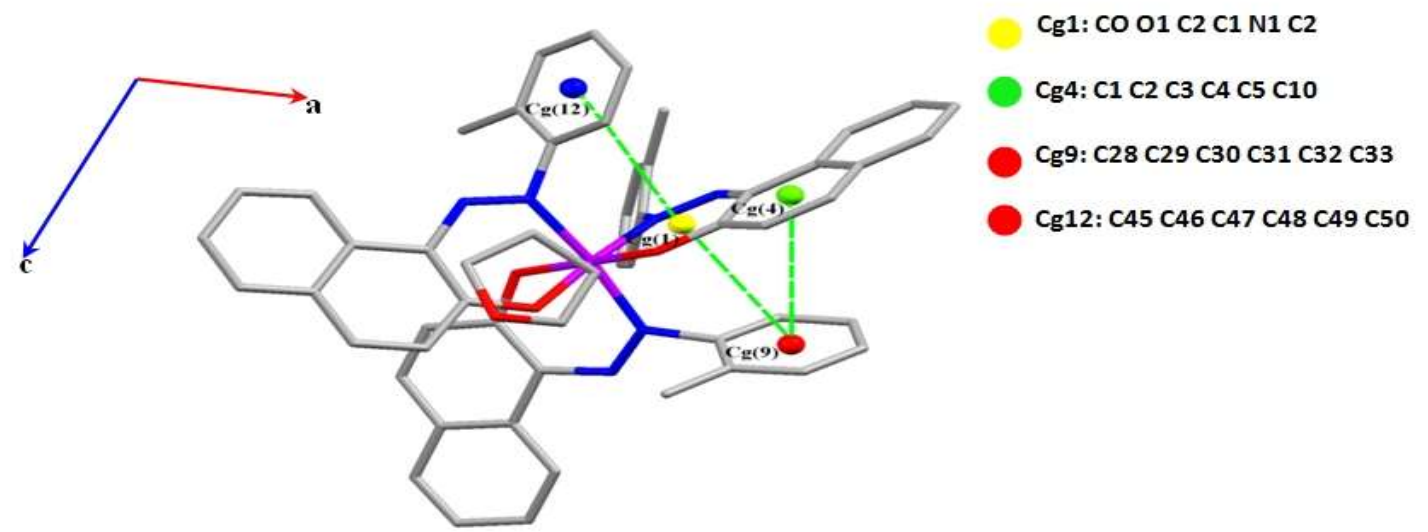

Figure 3. p-stacking.

The $\mathrm{C}-\mathrm{H} \cdots \pi \cdot \pi$ interactions generated by our complex are essentially of four types; the first is an intramolecular type interaction between $\mathrm{C} 17-\mathrm{H} 17 \mathrm{~B}$ and the center of gravity $\mathrm{Cg} 12$ with a distance $[\mathrm{C} 17-\mathrm{H} 17 \mathrm{~B} \cdots \cdot \mathrm{Cg} 12=2.69 \AA$ ] and the second is that observed between aromatic $\mathrm{CH}(\mathrm{C} 14-\mathrm{H} 14$, $\mathrm{C} 15-\mathrm{H} 15)$ and the centers of gravity $(\mathrm{Cg} 12, \mathrm{Cg} 9)$ of the benzene ring with distances [C14-H14 … Cg12 $=2.94 \AA$, and $\mathrm{C} 15-\mathrm{H} 15 \cdots \cdots . \mathrm{Cg} 9=2.90 \AA]$, the third observed between aromatic $\mathrm{CH}(\mathrm{C} 30-\mathrm{H} 30, \mathrm{C} 32-\mathrm{H} 32$ ) and the centers of gravity $(\mathrm{Cg} 11, \mathrm{Cg} 8)$ of the naphthalene ring with distances $[\mathrm{C} 30-\mathrm{H} 30 \cdots \cdot \mathrm{Cg} 11=$ $2.96 \AA$, and $\mathrm{C} 32-\mathrm{H} 32 \cdots . . \mathrm{Cg} 8=2.94 \AA]$. However the latter is linked the THF molecule with the complex, this distance interaction [C55-H55B $\cdots \cdot \mathrm{Cg} 10=2.79 \AA$ A (Figure 4). All of the C-H $\cdots \cdots \cdot \pi$ interactions are reported in Table 2.

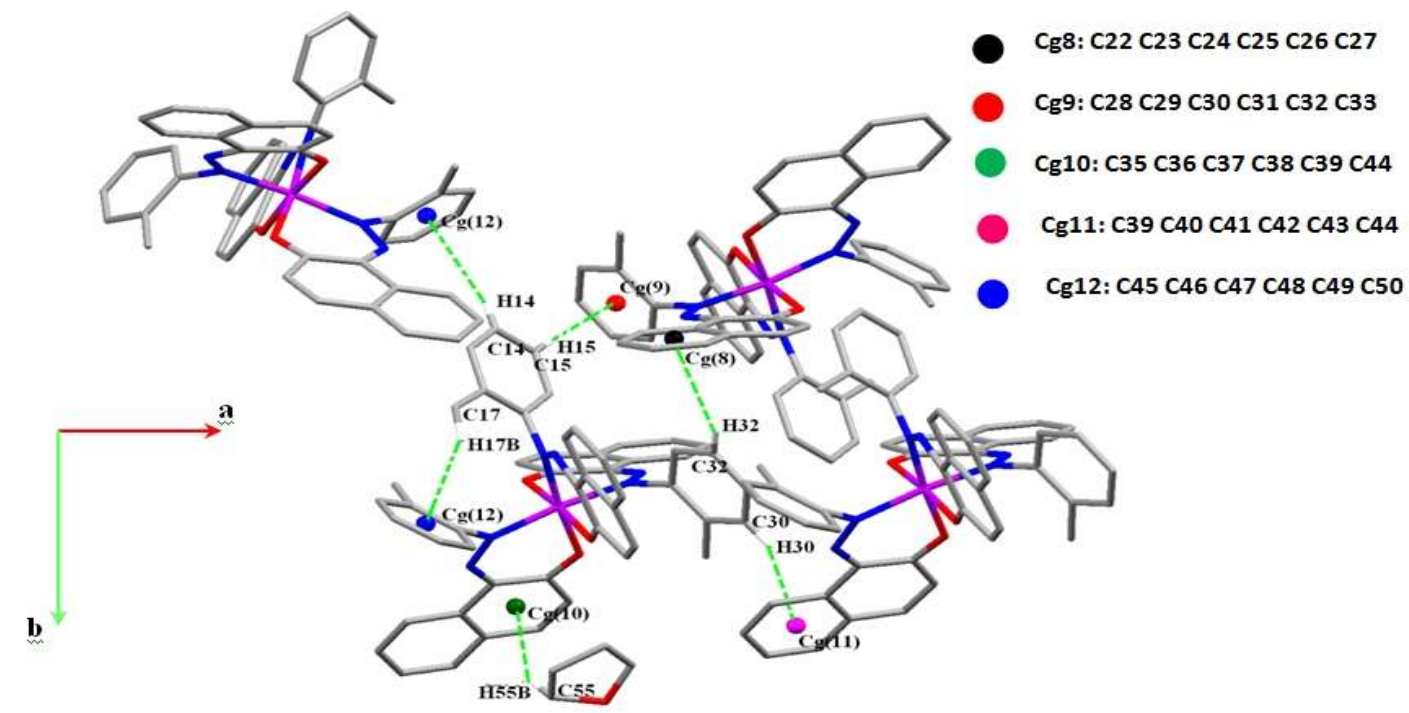

Figure 4. C-H $\cdots \cdots \pi$ interactions.

Table 2. interactions C-H....

\begin{tabular}{ccccc}
\hline $\mathbf{X - - H}(\mathbf{I})$ & $\mathbf{C g I}$ & $\mathbf{H} . . . \mathbf{C g}(\AA)$ & $\mathbf{X}) . . \mathrm{Cg}(\AA)$ & $\mathbf{X}-\mathbf{H} \ldots . . \mathbf{C g}\left({ }^{\circ}\right)$ \\
\hline $\mathrm{C}_{17}-\mathrm{H}_{178}$ & $\mathrm{Cg} 12^{\mathrm{i}}$ & 2.694 & 3.562 & 151 \\
\hline $\mathrm{C}_{14}-\mathrm{H}_{14}$ & $\mathrm{Cg} 12^{\text {ii }}$ & 2.938 & 3.803 & 155 \\
\hline $\mathrm{C}_{15}-\mathrm{H}_{15}$ & $\mathrm{Cg} 9$ iii & 2.903 & 3.828 & 173 \\
\hline $\mathrm{C}_{30}-\mathrm{H}_{30}$ & $\mathrm{Cg} 11^{\text {iv }}$ & 2.964 & 3.736 & 141 \\
\hline $\mathrm{C}_{32}-\mathrm{H}_{32}$ & $\mathrm{Cg} 8{ }^{\text {iii }}$ & 2.941 & 3.602 & 129 \\
\hline $\mathrm{C}_{50}-\mathrm{H}_{508}$ & $\mathrm{Cg} 10^{\mathrm{i}}$ & 2.788 & 3.669 & 151 \\
\hline
\end{tabular}


Symmetry codes: (i): X, Y, Z, (ii): $-X,-1 / 2+Y, 1 / 2$, (iii): Z1 - X, $1-Y, 1-Z$, (iv): $1+X, Y, Z$. Cg8: The centroids of the benzene ring (C22...C27). Cg9: The centroids of the benzene ring (C28...C33). Cg10: The centroids of the benzene ring (C35...C39-C44). Cg11: The centroids of the benzene ring (C39...C44). Cg12: The centroids of the benzene ring (C45...C50).

These distances suggest an arrangement, which is maintained united by p-stacking and $\mathrm{CH} / \mathrm{p}$ supramolecular interactions, which are observed between the centroids of the naphthol groups and $\mathrm{CH} / \mathrm{p}$, being notably important for the packaging of this crystalline system.

\section{Conclusions}

A coordination compound derived from 1- (o-tolyldiazenyl) naphthalen-2-ol were synthetized with cobalt ion present octahedron geometry. X-ray diffraction and spectroscopic methods: IR, $1 \mathrm{H}-\mathrm{NMR}$ among other techniques experimental and theoretical were used for structural elucidation of this compound. Supramolecular interactions based on p-stacking type between the two centroids from benzen rings were observed at $3.534 \AA$, $3.834 \AA$ and $3.759 \AA$; another important supramolecular interaction was observed between the $\mathrm{CH}$ from the phenyl group and the centroid of the benzen group, with the average distance of $3.600 \AA$.

\section{References}

1. Benaouida, M.A.; Benosmane, A.; Bouguerria, H.; Bouaoud, S.; Merazig, H. Acta Cryst. 2013, E69, m405.

2. Benosmane, A.; Benaouida, M.A.; Mili, A.; Bouchoul, A.; Merazig, H. Acta Cryst. 2015.

3. Mili, A.; Chetioui, S.; Rouag, D.-A.; Djukic, J.-P.; Bailly, C. IUCRDATA .1, X160691.(2016).

4. Ferreira, G.R.; de Oliveira, L.F.C. J. Mol. Struct. 2017, 1146, 50-56.

5. Al-Adilee, K.; Kyhoiesh, H.A.K. Preparation and identi fi cation of some metal complexes with new heterocyclic azo dye ligand 2-[2-(1-hydroxy-4-chloro phenyl) azo]-imidazole and their spectral and thermal studies. J. Mol. Struct. 2017, 1137, 160-178.

6. Gup, R.; Giziroglu, E.; Kırkan, B. Synthesis and spectroscopic properties of new azo-dyes and azo-metal complexes derived from barbituric acid and amino-quinoline. Dyes Pigment. 2007, 73, 40-46.

Publisher's Note: MDPI stays neutral with regard to jurisdictional claims in published maps and institutional affiliations.

(C) 2020 by the authors. Submitted for possible open access publication under the terms and conditions of the Creative Commons Attribution (CC BY) license (http://creativecommons.org/licenses/by/4.0/). 